\title{
SENTIMENTOS DE FAMILIARES ACOMPANHANTES DE ADULTOS FACE AO PROCESSO DE HOSPITALIZAÇÃO
}

\author{
Feelings of family companions of adults regarding hospitalization process
}

Sentimientos de los familiares acompañantes de adultos frente al proceso de hospitalización

\author{
Margrid Beuter ${ }^{1}$ \\ Franciele Roberta Cordeiro ${ }^{4}$
}

Cecília Maria Brondani ${ }^{2}$

Charline Szareski ${ }^{3}$

Camila Castro Roso ${ }^{5}$

\section{RESUMO}

0 estudo teve como objetivo descrever os sentimentos dos familiares acompanhantes durante a hospitalização de um membro da família e identificar as estratégias adotadas pela equipe de enfermagem para auxiliar o familiar acompanhante no enfrentamento da hospitalização do doente em uma unidade de clínica médica. Trata-se de uma pesquisa qualitativa, utilizando-se o Método Criativo e Sensivel para produção dos dados através da dinâmica "Almanaque". Os dados foram submetidos à análise de discurso francesa, emergindo dois temas: sentimentos de familiares acompanhantes oriundos do processo de hospitalização e estratégias da equipe de enfermagem para auxiliar o familiar acompanhante no enfrentamento da hospitalização do doente. Identificaram-se os sentimentos de solidão, abandono, apreensão, desespero e impotência. Constata-se que estratégias como a realização de grupos de apoio e de oração, a utilização da comunicação clara e coesa e o estabelecimento de uma relação solidária com o familiar acompanhante contribuirão na superação daqueles sentimentos.

Palavras-chave: Enfermagem. Hospitalização. Acompanhantes de pacientes.

\begin{abstract}
The following research was conducted aiming to describe the feelings of family companions during the hospitalization of family members and identify the strategies adopted by the nursing team to help the family companion in coping with the hospitalization in an internal medicine unit. This is a qualitative study, using the Creative and Sensitive Method for the production of data through the "Almanac" dynamic. Data were subjected to French discourse analysis emerging two topics: feeling of family companions from the hospitalization process and strategies of nursing team to help family companion in coping patient's hospitalization. Identify the feelings of loneliness, abandonment, apprehension, desperation, and impotence. Strategies like praying and support groups, the use of clear and cohesive communication and the establishment of a supportive relationship with a family companion will contribute in overcoming those feelings.
\end{abstract}

Keywords: Nursing. Hospitalization. Patient Escort Service.

\section{Resumen}

El estudio tuvo como objetivo describir los sentimientos de los familiares acompañantes durante la hospitalización de un miembro de su familia e identificar las estrategias adoptadas por el equipo de enfermería para auxiliar al familiar acompañante en el enfrentamiento de la hospitalización del enfermo en una unidad de clínica médica. La investigación utilizó el Método Creativo y Sensible para producir los datos. Se definieron dos temas: el sentimiento de familiares acompañantes provenidos del proceso de hospitalización y las estrategias del equipo de enfermería para auxiliar al familiar acompañante en el enfrentamiento de la hospitalización del enfermo. Se identificó los sentimientos de soledad, abandono, aprensión, desespero e impotencia. Se constata que las estrategias como la realización de grupos de apoyo y de oración, la utilización de la comunicación clara y cohesiva y el establecimiento de una relación solidaria con el familiar acompañante contribuirán en la superación de aquellos sentimientos.

Palabras clave: Enfermería. Hospitalización. Acompañantes de Pacientes

\footnotetext{
${ }^{1}$ Enfermeira, Doutora em Enfermagem pela Escola de Enfermagem Anna Nery da UFRJ. Professora Adjunto do Departamento de Enfermagem e do Programa de Pós-Graduação em Enfermagem (PPGEnf) da Universidade Federal de Santa Maria - UFSM. Membro do Grupo de Pesquisa Cuidado, Saúde e Enfermagem, Santa Maria-RS. Brasil. E-mail: margridbeuter@gmail.com; ${ }^{2}$ Enfermeira do Hospital Universitário de Santa Maria. Mestre em Enfermagem do PPGEnf da UFSM. Membro do Grupo de Pesquisa Cuidado, Saúde e Enfermagem, Santa Maria-RS. Brasil. E-mail: ceciliabrondani@hotmail.com; ${ }^{3}$ Enfermeira da Prefeitura Municipal de Caxias do Sul. Mestre em Enfermagem do PPGEnf da UFSM. Membro do Grupo de Pesquisa Cuidado, Saúde e Enfermagem, Caxias do Sul - RS. Brasil. E-mail: charlineszareski@yahoo.com.br; ${ }^{4}$ Acadêmica do 80 Semestre do Curso de Enfermagem da Universidade Federal de Santa Maria - Campus Santa Maria - UFSM, Membro do Grupo de Pesquisa Cuidado, Saúde e Enfermagem, Santa Maria-RS. Brasil. E-mail: francieleroberta1@hotmail.com; ${ }^{5}$ Enfermeira, Mestranda em Enfermagem do PPGEnf da UFSM, Bolsista CAPES. Membro do Grupo de Pesquisa Cuidado, Saúde e Enfermagem. Membro do Grupo de Pesquisa Cuidado, Saúde e Enfermagem, Santa Maria - RS. Brasil. E-mail: camilaroso@yahoo.com.br
} 


\section{INTRODUÇÃO}

0 envelhecimento da população tem ocasionado o aumento na incidência do número de doenças crônicodegenerativas. ${ }^{1}$ Geralmente estas doenças, no seu estágio mais avançado, levam a um longo período de permanência no hospital em decorrência da somatória progressiva de limitações físicas e alterações emocionais sofridas pelo paciente. Nessa situação, a presença de um familiar acompanhante pode ajudar a proporcionar apoio, segurança e tranquilidade, desde que aceita pelo doente e não imposta pela equipe, ou pela pressão do familiar.

A presença de familiares acompanhantes em unidades de internação tem gerado demandas para a equipe de enfermagem que estão relacionadas ao conhecimento e valores acerca das famílias que se encontram no espaço hospitalar. ${ }^{2} 0$ familiar precisa adequar-se às normas e rotinas que permeiam 0 ambiente hospitalar, tendo em vista o bem-estar do doente. ${ }^{3}$ Por suas características, neste espaço, a assistência é focada em procedimentos técnicos e na atenção à doença, sendo local de convivência com a dor e sofrimento das pessoas. Deste modo, a permanência neste ambiente, via de regra, não é agradável, nem acolhedora para os doentes e seus acompanhantes. ${ }^{4}$

"A doença provoca um impacto e desestrutura o universo familiar. 0 sofrimento em ver um ente querido ameaçado e sujeito a tratamentos agressivos, dor, dependência provoca uma série de sentimentos controversos" ${ }^{15: 108}$. Os sentimentos vivenciados pelo familiar acompanhante como o medo, a ansiedade e a insegurança são gerados, muitas vezes, pela falta de apoio, de atenção e de informações da equipe de saúde. A potencialização desses sentimentos pode ser justificada pela dificuldade da equipe de saúde em inserir a família no contexto da internação hospitalar. 0 interesse em participar do cuidado e a inter-relação do acompanhante com a equipe de enfermagem são elementos facilitadores ${ }^{6}$ para o processo de hospitalização aliado ao bem-estar do doente e seus familiares.

Criar estratégias para o enfrentamento dos desafios relacionados com o processo de hospitalização pode ser uma maneira de a equipe de enfermagem auxiliar o familiar acompanhante neste processo. ${ }^{4}$

A partir dessas considerações, tem-se como questão norteadora: Quais os sentimentos dos familiares acompanhantes diante da hospitalização de seu familiar? Com esta questão objetivou-se descrever os sentimentos dos familiares acompanhantes durante a hospitalização de um membro da família e identificar as estratégias adotadas pela equipe enfermagem para auxiliar o familiar acompanhante no enfrentamento da hospitalização do doente.

\section{METODOLOGIA}

Trata-se de uma pesquisa com abordagem qualitativa realizada com familiares acompanhantes de pessoas adultas acometidas de doenças crônicas internadas em uma unidade de clínica médica de um hospital público e de ensino no Rio Grande do Sul.

Participaram do estudo dez familiares acompanhantes, do sexo feminino, sendo cinco filhas, duas mães, uma esposa, uma nora e uma cunhada, que atenderam os critérios de inclusão do estudo: ser familiar acompanhante de um adulto internado há mais de três dias. Todas as familiares que participaram do estudo foram esclarecidas quanto ao Termo de Consentimento Livre e Esclarecido e, então, aceitaram a participação na pesquisa.

0 Método Criativo e Sensível (MCS) foi utilizado para a obtenção dos dados por meio de dinâmicas de criatividade e sensibilidade. ${ }^{7}$ Foram realizadas duas dinâmicas do tipo "Almanaque" no mês de março e de setembro de 2006. As duas Dinâmicas de Criatividade e Sensibilidade (DCS) ocorreram em cinco momentos.

No primeiro momento, as participantes foram recepcionadas em uma sala com cadeiras confortáveis, música no ambiente e lanche, quando foram apresentados os objetivos da pesquisa e as etapas da dinâmica.

No segundo momento, foram disponibilizados materias como revistas, canetas, papéis para a produção individual. As participantes trabalharam com recortes de gravuras e frases norteados pelas seguintes questões geradoras de debate: Quais são seus sentimentos diante da hospitalização do seu familiar? Como a equipe enfermagem pode ajudá-lo a enfrentar esse momento?

No terceiro momento, ocorreu a socialização dos dados produzidos, e, no quarto momento, concomitantemente aconteceram a análise grupal, as discussões acerca das produções artísticas e o dialogicismo entre as participantes. No quinto momento, ocorreram a síntese e a validação dos dados.

Cada dinâmica teve a participação de cinco sujeitos com uma duração em média de 50 minutos. Os dados produzidos nas dinâmicas foram registrados em um diário de campo, em um equipamento de gravação de áudio e posteriormente transcritos. Estes dados foram analisados seguindo os pressupostos da análise de discurso francesa. ${ }^{8}$ Para a análise dos dados foram elaborados quadros analíticos que possibilitaram o desvelamento dos temas.

Os aspectos éticos da pesquisa seguiram a Resolução 196/96 do Conselho Nacional de Saúde, que dispõem sobre as Normas de Pesquisa com Seres Humanos. A investigação foi aprovada pelo Comitê de Ética em Pesquisa da instituição sob o n ${ }^{0}$ 120/05 em 12 de dezembro de 2005. Sendo assim, as acompanhantes participaram do estudo de forma voluntária, garantindo-se 0 anonimato, por meio da utilização 
dos seguintes pseudônimos: Irene, Alice, Carla, Elisa, Rosa, Sônia, Denise e Cristina.

\section{RESULTADOS E DISCUSSÃO}

A análise dos dados conduziu ao primeiro tema sentimentos de familiares acompanhantes oriundos do processo de hospitalização desvelado nos subtemas: o sentimento de desamparo do familiar acompanhante; o impacto do familiar acompanhante diante da hospitalização do doente; a ruptura das relações sociais do familiar acompanhante; a confiança nos recursos tecnológicos e religiosos; a solidariedade entre os familiares acompanhantes; e ao segundo tema — estratégias da equipe de enfermagem para auxiliar o familiar acompanhante no enfrentamento da hospitalização do doente.

\section{Sentimentos de familiares acompanhantes oriundos do processo de hospitalização}

A hospitalização causa no familiar um sentimento ambíguo. Por um lado ser cuidador proporciona compaixão e gratificação ao ajudar uma pessoa que se encontra enferma, debilitada e longe de seu cotidiano de vida. Por outro lado, é um momento de fragilidade que envolve o familiar acompanhante, a pessoa doente e os demais membros da família. Esses sentimentos foram expressos nos temas e subtemas que emergiram durante a realização das dinâmicas

\section{0 sentimento de desamparo do familiar acompanhante}

No movimento dialógico no interior das dinâmicas, as familiares acompanhantes desvelaram o tema por meio das falas:

[...] os familiares, a maioria, sumiu nessa hora, ficou só eu e uma madrinha minha que também é doente [...] (Irene).

Setufalar com cinquentaacompanhantes de pacientes, quarenta enove se queixam dos parentes. Porque não ajudam a cuidar os pacientes [...] (Elisa).

\section{Éverdade! (Alice)}

Com minha cunhada já é diferente, né! Ela tem só dois filhos, né! E todos os parentes [...] a outra cunhada dela, e a nora dela, todos vem, todos os dias, vem um, vem outro. Sempre tem. (Carla)

As participantes do estudo revelaram que muitos familiares não contam com o apoio dos demais membros da família para acompanhar o paciente no hospital, realizando estas atividades sozinhas. Por essa razão sentem-se abandonadas e vivenciam o sentimento de solidão. Entretanto, quando há a corresponsabilização de todos os integrantes da família no cuidado ao doente, este sentimento de abandono pode ser amenizado, pois evita a sobrecarga de uma pessoa por meio do compartilhamento do cuidar ${ }^{6}$, como foi verificado no relato de Carla.

Outra fala complementa a discussão quando diz:

[...] eu estou aqui cuidando, mas... Por que outras pessoas não vêm aqui? Não querem vir? [...] Ela (a mãe) tem vários irmãos, cunhados, tios, sobrinhos e ninguém vem. No meu caso, tios, primos e até o namorado que eu tinha se estressou com a doença da minha mãe e também se foi [...] (Irene).

A hospitalização prolongada geralmente tem como consequência a sobrecarga de um familiar cuidador. Por diversos fatores, a responsabilidade do cuidado, recai por vezes, em um único membro da família. ${ }^{9} \mathrm{~A}$ falta de ajuda de familiares ou amigos é considerada pelos cuidadores uma situação inaceitável, pois a família é vista como o sustentáculo em momentos de crise. Os familiares visitantes e acompanhantes de idosos hospitalizados ${ }^{3}$ consideram que a família tem obrigação moral em oferecer suporte a um ente em situação de vulnerabilidade.

No entanto, em outro relato:

Por enquanto eu não me queixo, porque nós, nossos amigos, enquanto ele era são [...] a gente pescava. Todo final de semana, ninguém achava a gente em casa. A gente fazia quilômetros pra ir pescar ... mas ninguém nos abandonou. Faz três anos que nós não saímos mais pra pesca, nada de pesca. Mas a turma de amigo continuou. (Elisa)

Na situação da Elisa, a família conta com o apoio dos amigos nos bons e maus momentos. A presença de amigos em momentos de doença e sofrimento pode ajudar a diminuir 0 sentimento de desamparo que outras familiares relataram.

0 sentimento de desamparo ainda é manifestado nas falas de outras participantes, ao demonstrarem a sua inconformação com a situação vivenciada:

[...] às vezes me pergunto: "Por que está me acontecendo isso?" Eu fiz tanto bem para pessoas, com certeza. Pode até pesquisar na minha cidade [...] (Rosa).

Eu também digo a mesma coisa, sou uma pessoa tão boa com todo mundo. Por que Deus está fazendo isso comigo? Não éjusto, né? [...] (Sônia).

As acompanhantes, ao vivenciarem a doença do seu familiar, sentem-se por vezes, injustiçadas, questionando-se o porquê de estarem passando por isso. Nesse contexto, emerge a questão da espiritualidade na tentativa de buscar explicações para a condição de doença 
Beuter M, Brondani CM, Szareski C, Cordeiro FR, Roso CC

e de sofrimento vivenciadas. Muitos familiares, assim como os pacientes, atribuem a situação de doença a alguma má ação ou a algum castigo divino.

A doença de um ente querido gera sofrimentos de diversas naturezas e questionamentos em relação à situação vivida pela família. Estes questionamentos podem ser considerados etapas a serem superadas para a aceitação da nova realidade - conviver com a doença de um familiar. ${ }^{10}$

\section{0 impacto do familiar acompanhante diante da hospitalização do doente}

A hospitalização para a família pode ser considerada um acontecimento chocante, pois ela se depara com uma realidade desconhecida, assustadora e repleta de incertezas no qual o seu familiar está inserido. No âmbito da dinâmica foi desvelado o tema, que foi expresso nas falas a seguir:

[...] ver ela (a mãe) toda entubada, no momento que eu vi eu me desesperei. Eu achei que ela não ia durar dois dias [...] (Denise).

[...] ah! Não me sinto bem, os doentes, os aparelhos [...] (Cristina).

0 contato com o ambiente hospitalar, os outros doentes e o familiar envolto em aparelhos, geram mal-estar e desconforto nas acompanhantes, associado ao fato de a família encontrar-se fragilizada e abalada emocionalmente.

A realização de procedimentos invasivos como a intubação, as punções venosas, as aspiraç̃̃es, os cateterismos e todo o aparato tecnológico utilizado para o monitoramento do paciente causa impacto no familiar. Os familiares assustam-se, pois não estão acostumados com todos esses instrumentos que modificam e deformam a estética do paciente. Estas situaç̃es, aliadas à falta de explicações da equipe de saúde sobre a finalidade dos aparelhos e a realização das técnicas, geram sentimento de apreensão, desespero e impotência nos familiares.

0 desconhecimento sobre o quadro clínico do doente aumenta a preocupação do familiar acompanhante, conforme a fala:

[...] aqui a gente fica muito sem saber o que vai acontecer. Eles (médicos) passam com muita pressa, você não tem esclarecimento para te deixar calma [...] (Rosa).

A falta de diálogo impossibilita o estabelecimento de vínculo da equipe de saúde com os familiares, levando ao cuidado meramente técnico, ao distanciamento dos profissionais da família e à escassez de informações. ${ }^{6} 0$ fornecimento de informações aos familiares sobre as condições do doente, tratamento e procedimentos desenvolvidos contribui para

diminuir o estresse e auxiliá-los a suportar a experiência da hospitalização. ${ }^{11}$

\section{A ruptura das relações sociais do familiar acompanhante}

A diminuição da convivência social do familiar acompanhante ocorre em decorrência da interrupção nas suas atividades do cotidiano durante o período que permanece no hospital, ocasionando o isolamento social, como foi desvelado nas falas:

[...] no meu caso, a vida estacionou, parou. Eu passei esses últimos quatro meses vivendo para minha mãe. Eu tinha uma vida agitada, eu tinha um círculo de amigos, um grupo que eu frequentava, eu tive que parar o colégio porque não deu para conciliar [...] (Irene).

[...] é que a vida parece que fica em suspense [...] (Alice).

[...] a vida parou [...] (Elisa).

0 cotidiano do cuidado, tanto no ambiente hospitalar quanto no domiciliar, acarreta privações e abnegações, podendo causar sensação de perda de liberdade quando o cuidador não conta com o auxílio de outras pessoas para compartilhar a tarefa de cuidar. Essa rotina de cuidado inviabiliza a necessidade de liberdade do ser humano. A satisfação da liberdade ${ }^{12}$ possibilita o bem-estar e o confor to de saber ou descobrir ser dono de si, sendo uma forma de vida que expressa o cuidado de si.

\section{A confiança nos recursos tecnológicos e religiosos}

No movimento dialógico, no âmbito das dinâmicas, os sentimentos de confiança foram desvelados nas falas:

[...] me sinto confortável por saber que estou no meio do recurso, que a minha filha está sendo bem cuidada e com uma grande possibilidade de sarar [...] (Rosa).

[...] cheguei aqui, eu vi recurso, né? Daí eu me senti... comecei a me sentir um pouco melhor [...] (Sônia).

[...] estamos no recurso. Temos doutor, temos as enfermeiras, estamos bem, não preciso me preocupar [...] (Denise).

Os familiares demonstram a segurança que sentem percebendo a disponibilização dos recursos tecnológicos e dos serviços da equipe de saúde na busca do tratamento e recuperação do doente. 
A confiança em um ser superior proporciona força e esperança às familiares acompanhantes, como demonstram os discursos:

[...] tenho aquela esperança. Até que exista uma respiração, eu acredito que tudo é possível, eu não sei, mas eu acho que épela féque tenho [...] (Rosa).

[...] e graças a Deus, Deus está me dando, bastante força para isso. Acho que no máximo semana que vem o médico vai dar alta [...] (Sônia).

As falas indicam a importância da religiosidade para o enfrentamento da hospitalização do familiar doente. A religiosidade é um sentimento íntimo na conviç̧ão da existência de uma força superior envolvendo a vida das pessoas, ${ }^{13}$ protegendo e dando sentido à existência humana, fugindo aos padrões de nossa exata compreensão. A crença em um ser superior capaz de promover a cura e fazer o impossível, independentemente de religião, proporciona a autoconfiança no cuidador, gerando a esperança na recuperação da saúde do ente querido.

\section{A solidariedade entre os familiares acompanhantes}

Outro sentimento desvelado pelas familiares foi a solidariedade, que surge à medida que elas ajudam o seu familiar no cuidado, bem como outros doentes que não dispõem de acompanhantes, como pode ser verificado nas falas:

[...] eu me sinto assim, tão feliz de estar ajudando, porque é uma coisa que eu gosto muito [...] (Sônia).

[...] me sinto feliz em poder ajudar, né! 0 pouco que tenho eu divido assim [...] (Denise).

[...] estou me sentindo útil, porque não só estou ajudando ele (sogro), mas ajuda, a gente cuida, dá uma olhadinha, a gente vai se ajudando, vai fazendo amizade [...] (Alice).

É possível perceber a formação de redes de apoio entre os familiares acompanhantes, que se solidarizam uns com os outros, trocam experiências sobre as formas de cuidar, além de compartilharem os sentimentos vivenciados durante o período de hospitalização. Essa interação possibilita o fortalecimento desses familiares, contribuindo para o enfrentamento da situação vivenciada, por meio da compaixão, solidariedade e da confiança na recuperação de seu familiar doente.

A solidariedade ${ }^{3}$ pode ser compreendida como uma norma que permeia as relações próximas. Ela pode ser representada por atitudes de amor, amizade, senso de justiça, colaboração e respeito com o outro. 0 período da hospitalização contribui para que as acompanhantes se conheçam melhor, percebam que possuem capacidade de cuidar e de ajudar, o que surpreende a algumas, e com isso elas melhoram sua autoestima.

[...] porque eu estou ajudando os outros ali. Tem gente pior que a gente, né? Todo mundo diz assim, que sou uma guerreira! Claro eu sou! [...] (Denise).

[...] e eu fiquei surpresa comigo mesma, eu nunca imaginei que eu tivesse, força pra ajudar ele (sogro) [...] (Alice).

0 cuidar de outra pessoa pode ser uma oportunidade de crescimento e realização pessoal na medida em que promove a mudança de atitudes e valores individuais e a expressão de sentimentos de solidariedade, amor e empatia. A experiência de cuidar de familiares com doença Alzheimer constitui-se em uma possibilidade de exercício da dignidade, do respeito, da afetividade e do amor ao próximo. ${ }^{14} 0$ amor $^{15}$ é um fenômeno biológico e cósmico, que dá origem à sociedade. Na humanidade este sentimento revela-se como força agregadora de simpatia e de solidariedade.

Estratégias da equipe de enfermagem para auxiliar - familiar acompanhante no enfrentamento da hospitalização do doente

A partir da questão geradora de debate "Como a equipe de enfermagem pode ajudá-lo a enfrentar esse momento?" enunciada nas duas dinâmicas do tipo "Almanaque", as participantes trouxeram para o espaço de discussão grupal as estratégias adotadas pela equipe de enfermagem para auxiliar o familiar acompanhante no enfrentamento da hospitalização.

A realização de grupos de apoio foi apontada como uma estratégia importante, pois possibilita o compartilhamento de sentimentos e vivências entre as familiares e opor tuniza o esclarecimento de dúvidas sobre as condições do doente e seu tratamento com os profissionais de saúde. Um estudo ${ }^{16}$ aponta o grupo de suporte como uma estratégia importante para satisfazer as necessidades de informações e apoio emocional para familiares de pacientes internados em UTI. Deste modo, foi possível ajudá-los a se sentirem acolhidos na instituição, enfrentando este momento crítico.

Os familiares citaram grupo de oração como uma estratégia que os fortalece no momento da doença e da hospitalização. A par ticipação neste grupo foi apontada como uma forma de encontro consigo mesmo, buscando na força divina, coragem, esperança e confiança no tratamento e na recuperação da saúde do familiar doente. A prática religiosa ${ }^{17}$ propicia ao paciente e sua família um modo de buscar um sentido para a situação vivenciada.

Outra estratégia, a comunicação entre os familiares e a equipe de saúde, de forma clara e coesa, é relatada como um dos aspectos mais importantes na valorização do familiar 
acompanhante durante a hospitalização. A comunicação é considerada a base de todo o relacionamento humano, não sendo diferente no ambiente hospitalar. A relação da equipe de saúde com os familiares, por vezes, torna-se difícil devido à divergência entre os conhecimentos compartilhados. Deste modo, o estabelecimento de uma relação dialógica e coesa entre o familiar e a equipe de saúde ajuda a integrá-lo nas decisões a serem adotadas em relação ao tratamento do doente.

A consolidação de um relacionamento afetivo, respeitoso e solidário da equipe de saúde com os familiares foi outro aspecto ressaltado. A equipe pode, nesse sentido, agir com carinho, dirigir palavras de conforto, ouvir e solidarizar-se com os familiares, preocupando-se em minimizar os sentimentos de insegurança, aflição e ansiedade dos acompanhantes.

A prática de atividades lúdicas foi apontada pelos familiares como meio de enfrentamento e minimização da tensão representada pelo cenário hospitalar. A utilização do diálogo carinhoso, da prática de leituras, utilização de atividades recreativas que visem melhorar a harmonia do ambiente $\mathrm{e}$ diminuam o sofrimento vivenciado são estratégias que a equipe de enfermagem pode adotar no desenvolvimento de um cuidado criativo e sensível, pois promovem a humanização da assistência de enfermagem. Quando a equipe de enfermagem interage com os familiares acompanhantes e doentes proporcionando um ambiente agradável, por meio da música, das conversas, das brincadeiras, emerge o lúdico como elemento qualificador do cuidado de enfermagem que se expressa com criatividade $e$ sensibilidade no ato de cuidar. ${ }^{18}$

\section{CONSIDERAÇÕES FINAIS}

O sentimento de solidão e abandono foi desvelado pelos familiares acompanhantes durante a hospitalização do doente, mas amenizado quando houve corresponsabilização dos demais membros da família no cuidado ao doente. A falta de orientações e de diálogo da equipe de saúde provocou o sentimento de apreensão, desespero e impotência nos familiares. Este fato pode ser relacionado com outro sentimento, a sensação de perda de liberdade quando o familiar acompanhante não contou com o auxilio de outras pessoas para compartilhar a tarefa de cuidar.

Em contrapartida, verificou-se que o sentimento de segurança foi percebido com a disponibilização dos recursos tecnológicos e dos serviços da equipe de saúde. Os sentimentos de religiosidade e de solidariedade foram considerados importantes para o enfrentamento da hospitalização do familiar doente, bem como de outros doentes sem acompanhantes.

Uma das estratégias adotadas pela equipe de enfermagem para auxiliar o familiar acompanhante no enfrentamento da hospitalização do doente foi a realização de grupos de apoio para o compartilhamento de sentimentos, vivências entre os familiares e o esclarecimento de dúvidas. Outra estratégia identificada foi o grupo de oração apontado como uma maneira de buscar na força divina a coragem, a esperança e a confiança no restabelecimento do seu familiar. A comunicação clara e coesa associada ao relacionamento respeitoso e solidário da equipe de saúde com os familiares foi uma estratégia considerada importante. A estratégia da prática de atividades lúdicas foi ressaltada como uma foma de diminuir a tensão durante a hospitalização do doente.

Ressalta-se a importância da contribuição do familiar acompanhante no processo de hospitalização do doente. 0 familiar vivencia momentos gratificantes e, também, angustiantes, em um turbilhão de sentimentos que revelam sensações ambíguas. Na busca da superação desta condição, há necessidade de lançar mão de estratégias. A concretização das estratégias envolve fatores subjetivos, de decisões e escolhas. Enfim, o enfrentamento da hospitalização pelo familiar cuidador comporta iniciativas singulares.

\section{REFERÊNCIAS}

1 Santos AA, Pavarini SCl, Brito TRP. Perfil dos idosos com alterações cognitivas em diferentes contextos de vulnerabilidade social. Esc Anna Nery. 2010 jul-set; 14(3): 496-503.

2 Monticelli M, Boehs AE. A família na unidade de internação hospitalar: entre o informal e o instituído. Rev Esc Enferm USP. 2007 set; 41(3): 468-77.

3 Silva L, Bocchi SCM, Bousso RS. 0 papel da solidariedade desempenhado por familiares visitantes e acompanhantes de adultos e idosos hospitalizados. Texto\& Contexto Enferm. 2008 abr-jun; 17(2): 297-303.

4 Beuter M, Brondani CM, Szareski C, Lana LD, Alvim NAT. Perfil de familiares acompanhantes: contribuições para a ação educativa da enfermagem. Rev Min Enferm. 2009 jan-mar; 13(1): 28-33.

5 Waldow VR. 0 cuidado na saúde: as relações entre o eu, o outro e 0 cosmos. Petrópolis(RJ): Vozes; 2004.

6 Penna SB, Diogo MJD. Fatores que favorecem a participação do acompanhante no cuidado do idoso hospitalizado. Rev Latino-am Enfermagem. 2005 set-out; 13 (5): 663-69.

7 Cabral IE. Aliança de saberes no cuidado e estimulação da criança-bebê: concepções de estudantes e mães no espaço acadêmico de enfermagem. Rio de Janeiro: UFRJ/EEAN; 1999.

8 Orlandi EP. Análise de discurso: princípios e procedimentos. $4^{\mathrm{a}}$ ed. Campinas: Pontes; 2002.

9 Souza LM, Wegner W, Gorini MIPC. Educação em saúde: uma estratégia de cuidado ao cuidador leigo. Rev Latino-am Enfermagem. 2007 marabr; 15(2): 337-43.

10 Silveira TM, Caldas CP, Carneiro TF. Cuidando de idosos altamente dependentes na comunidade: um estudo sobre cuidadores familiares principais. Cad Saude Publica. 2006 ago; 22(8):1629-38. 
11 Santos AF, Campos MA, Dias SFP, Cardoso TVM, Oliveira ICS. 0 cotidiano da mãe com seu filho hospitalizado: uma contribuição para a enfermagem pediátrica. Rev Enferm UERJ. 2001 dez; 5(3): 325-34.

12 Schossler T, Crossetti MG. Cuidador domiciliar de idoso e o cuidado de si: uma análise através da teoria do cuidado humano de Jean Watson. Texto\&Contexto Enferm. 2008 abr-jun; 17(2): 280-87.

13 Valente NMLM, Bachion MM, Munari DB. A religiosidade dos idosos: significados, relevância e operacionalização na percepção dos profissionais de saúde. Rev Enferm UERJ. 2004 jan-abr; 12(1):11-7.

14 Sena ELS, Gonçalves LHT. Vivência de familiares cuidadores de pessoas idosas com doença de Alzheimer: perspectiva de Merleau-Ponty. Texto\&Contexto Enferm. 2008 abr-jun; 17(2): 232-40.

15 Boff L. Saber cuidar, ética do humano: compaixão pela terra. Petrópolis (RJ): Vozes; 1999.

16 Oliveira LMAC, Medeiros M, Barbosa MA, Siqueira KM, Oliveira PMC, Munari DB. Grupo de suporte como estratégia para acolhimento de familiares de pacientes em Unidade de Terapia Intensiva. Rev Esc Enferm USP. 2010 jun; 44 (2): 429-36.

17 Silva L, Moreno V. A religião e a experiência do sofrimento psíquico: escutando a Cienc Cuid Saude. 2004 maio/ago; 3(2): 161-68.

18 Beuter M, Cordeiro FR, Quinhones SMW, Lima MGR, Brondani CM. 0 teatro como estratégia lúdica no cuidado ao doente hospitalizado. Rev Enferm UFPE On Line [serial on-line]. 2010; [cited 2010 ago 5] 4(1):

Available from: http://www.ufpe.br/revistaenfermagem/index.php/revista/ article/view/583/486 